\title{
To the Editor-Interpretation of electrograms is key to understand the clinical potential of ECGI
}

Citation for published version (APA):

Cluitmans, M. J. M., Stoks, J., \& Volders, P. G. A. (2019). To the Editor-Interpretation of electrograms is key to understand the clinical potential of ECGI. Heart Rhythm, 16(6), E51-E52.

https://doi.org/10.1016/j.hrthm.2019.02.030

Document status and date:

Published: 01/06/2019

DOI:

10.1016/j.hrthm.2019.02.030

Document Version:

Publisher's PDF, also known as Version of record

Document license:

Taverne

Please check the document version of this publication:

- A submitted manuscript is the version of the article upon submission and before peer-review. There can be important differences between the submitted version and the official published version of record.

People interested in the research are advised to contact the author for the final version of the publication, or visit the DOI to the publisher's website.

- The final author version and the galley proof are versions of the publication after peer review.

- The final published version features the final layout of the paper including the volume, issue and page numbers.

Link to publication

\footnotetext{
General rights rights.

- You may freely distribute the URL identifying the publication in the public portal. please follow below link for the End User Agreement:

www.umlib.nl/taverne-license

Take down policy

If you believe that this document breaches copyright please contact us at:

repository@maastrichtuniversity.nl

providing details and we will investigate your claim.
}

Copyright and moral rights for the publications made accessible in the public portal are retained by the authors and/or other copyright owners and it is a condition of accessing publications that users recognise and abide by the legal requirements associated with these

- Users may download and print one copy of any publication from the public portal for the purpose of private study or research.

- You may not further distribute the material or use it for any profit-making activity or commercial gain

If the publication is distributed under the terms of Article $25 \mathrm{fa}$ of the Dutch Copyright Act, indicated by the "Taverne" license above, 


\section{References}

1. Duchateau J, Sacher F, Pambrun T, et al. Performance and limitations of noninvasive cardiac activation mapping. Heart Rhythm 2019;16:435-442.

2. Ramanathan C, Jia P, Ghanem R, Ryu K, Rudy Y. Activation and repolarization of the normal human heart under complete physiological conditions. Proc Natl Acad Sci U S A 2006;103:6309-6314.

3. Ghanem RN, Burnes JE, Waldo AL, Rudy Y. Imaging dispersion of myocardial repolarization, II: noninvasive reconstruction of epicardial measures. Circulation 2001;104:1306-1312.

4. Zhang J, Hocini M, Strom M, et al. The electrophysiological substrate of early repolarization syndrome: noninvasive mapping in patients. JACC Clin Electrophysiol 2017;3:894-904.

Reply to the Editor-Performance and

limitations of noninvasive cardiac activation mapping

We thank Dr Rudy for his remarkable contribution to the development of noninvasive electrocardiographic (ECG) mapping and for his interest in our work. ${ }^{1}$ The term ECGi was used in reference to an epicardial potential formulation using the method of fundamental solutions, as termed in previous publications. This method is used in the commercial system we evaluated. Historical validation of ECGi was performed by studying animal hearts placed in a tank filled with conductive saline, which we believe may overestimate the accuracy of the reconstruction. Our goal was to evaluate ECGi under clinical conditions.

Contact unipolar maps were annotated using a maximal -dV/dT approach, identical to ECGi. Example maps constructed from unipolar contact signals are available in the Supplemental Material, and readers will observe that the differences with bipolar maps are minor. We have also compared contact bipolar- to unipolar-based annotation in other patients (Rhythmia system) and observed little change in activation.

Breakthrough sites were defined using activation mapping - the focus of this work-similar to other studies. ${ }^{2}$ This approach has the advantage of being unambiguous and automatic. In contrast, the "center of earliest persistent minimum" lacks a precise definition and, in our opinion, requires further studies.

Repolarization times were not evaluated because they cannot be reliably acquired using a point-by-point methodology. We have implied that repolarization mapping should be subject to caution because they are based on the same reconstruction scheme as activation mapping. The studies referenced by Dr Rudy as validation have not compared noninvasive and invasive repolarization measurements.

Lines of block are mostly due to structural anomalies and are fixed at stable physiological rates. Using invasive mapping as the gold standard, our findings provide unequivocal evidence that those imaged by ECGi were artificial.

In summary, we want to emphasize that ECGi activation mapping is relatively accurate for single-site breakthroughs (pacing or ectopy) but insufficient for this use during sinus rhythm (multiple breakthroughs). We do not believe that expert editing is a sufficient answer to these shortcomings.
Among other options, artificial intelligence may help improve noninvasive mapping, but probably in inverse reconstruction itself rather than in postprocessing. Whatever the proposed solutions, this work highlights the necessity of their clinical validation.

Josselin Duchateau, MD, MSc josselin.duchateau@ihu-liryc.fr Michel Haïssaguerre, MD Rémi Dubois, PhD

Bordeaux University Hospital, IHU LIRYC Bordeaux, France Hôpital Cardiologique du Haut Lévèque, CHU de Bordeaux Pessac, France

\section{References}

1. Duchateau J, Sacher F, Pambrun T, et al. Performance and limitations of noninvasive cardiac activation mapping. Heart Rhythm 2019;16:435-442.

2. Andrews CM, Srinivasan NT, Rosmini S, et al. Electrical and structural substrate of arrhythmogenic right ventricular cardiomyopathy determined using noninvasive electrocardiographic imaging and late gadolinium magnetic resonance imaging. Circ Arrhythm Electrophysiol 2017;10:e05105.

\section{To the Editor-Interpretation of electrograms is} key to understand the clinical potential of ECGI

With great interest we read the article of Duchateau et $\mathrm{al}^{1}$ on clinical validation of noninvasive electrical activation mapping by comparing electrocardiographic imaging (ECGI) with epicardial invasive contact mapping. We commend the authors for performing this much-needed study, which helps to further define the value of ECGI in the cardiology clinic. Overall, we find the approach of these investigators sound, but we also consider that the study falls short of explaining the reported discrepancies.

Interpretation of the underlying recorded and reconstructed electrograms is key to the results. However, electrogram morphology was not systematically assessed. In our in vivo animal validation study, we recorded epicardial electrograms with implanted electrodes, simultaneous to ECGI. ${ }^{2}$ We concluded that a spatial shift (due to cardiac motion or geometrical inaccuracies) of the recorded vs reconstructed electrograms results in low correlations. Compensating for these spatial mismatches improved the correlations. ${ }^{2}$

In addition, we found most low correlations in myocardial regions of gradual change in electrogram morphology (eg, polarity switch). During the electrographic transition in these regions, multiple deflections were present, and selecting the right "activation time" is not trivial. We demonstrated that activation time accuracy improved when not only temporal but also spatial characteristics of the activation wavefront were taken into account. ${ }^{2}$ The influence of the postprocessing algorithm used to determine the activation time from the electrogram, although emphasized by the authors previously, ${ }^{3}$ is not assessed in the present study. Overall, these various aspects may also explain the apparently lower resolution of 
ECGI activation maps compared to the authors' previous publications.

We agree that the current performance of ECGI is likely lower than that of invasive (high-density) contact mapping, but without the possibility to analyze local electrograms and the effect of postprocessing algorithms, the authors' value judgment of ECGI in patients and its perspectives may be more negative than warranted.

Matthijs J.M. Cluitmans, MD, PhD m.cluitmans@maastrichtuniversity.nl Job Stoks, MSc Paul G.A. Volders, MD, PhD

Department of Cardiology Maastricht University Maastricht, The Netherlands

\section{References}

1. Duchateau J, Sacher F, Pambrun T, et al. Performance and limitations of noninvasive cardiac activation mapping. Heart Rhythm 2019;16:435-442.

2. Cluitmans MJM, Bonizzi P, Karel MH, et al. In vivo validation of electrocardiographic imaging. JACC Clin Electrophysiol 2017;3:232-242.

3. Duchateau J, Potse M, Dubois R. Spatially coherent activation maps for electrocardiographic imaging. IEEE Trans Biomed Eng 2016;64:1149-1156.

Reply to the Editor-Interpretation of electrograms is key to understand the clinical potential of ECGi

We thank Cluitmans et al for their interest in our work and for pinpointing some of the key challenges in electrocardiographic imaging.

Postprocessing of electrograms (EGMs) is a nontrivial task, and questions as to whether this step had an influence on the final results warrant our interest. Our correspondents suggest that a spatiotemporal approach may substantially improve the reconstruction.

In a previous work, we have indeed observed an improvement in the quality of activation maps with the use of a spatiotemporal approach, ${ }^{1}$ but this improvement was minimal and cannot explain the significant differences between epicardial and body surface recordings. In addition, $-\mathrm{dV} / \mathrm{dT}$ is the most widely used approach for unipolar EGM annotation, both for invasive and for noninvasive unipolar signals; and contact maps annotated using bipolar signals (analog to a spatial derivative) were highly correlated with contact unipolar maps (see the Online Supplement ${ }^{2}$ ), which suggests that their combination in a "spatiotemporal approach" would not substantially modify the results. These observations indicate that the main map discrepancies come from the EGMs themselves and not the annotation scheme.

In a previous study, our correspondents have shown that cardiac motion may degrade reconstructions and propose to time-shift recorded EGMs as a correction, which is an interesting point. ${ }^{3}$ In our study, it is important to note that map correlation was poorest in patients with narrow $\mathrm{QRS}$ morphology, for which cardiac motion during ventricular activation is minimal, as compared to cardiac pacing.

The divergence between our study and previous publications can be explained by different factors. ${ }^{2}$ We have highlighted differences between experimental and clinical conditions, and between paced and conducted QRS. Furthermore, our analysis was focused on individual map pair comparison, a metric we believe to have more clinical meaning than global correlation across subjects.

Josselin Duchateau, MD, PhD josselin.duchateau@ihu-liryc.fr Michel Haïssaguerre, MD Rémi Dubois, PhD

Bordeaux University Hospital and IHU LIRYC Bordeaux, France Hôpital Cardiologique du Haut Lévèque CHU de Bordeaux Pessac, France

\section{References}

1. Duchateau J, Potse M, Dubois R. Spatially coherent activation maps for electrocardiographic imaging. IEEE Trans Biomed Eng 2017;64:1149-1156.

2. Duchateau J, Sacher F, Pambrun T, et al. Performance and limitations of noninvasive cardiac activation mapping. Heart Rhythm 2019;16:435-442.

3. Cluitmans MJM, Bonizzi P, Karel JMH, et al. In vivo validation of electrocardiographic imaging. JACC Clin Electrophysiol 2017;3:232-242. 